\title{
Relationship between Extraversion and Employees' Innovative Behavior and Moderating Effect of Organizational Innovative Climate
}

\begin{abstract}
Yuyan Luo ${ }^{1,2}$, Zhi Cao ${ }^{1}$, Lu Yin ${ }^{1}$, Huiqin Zhang ${ }^{1}$, Zhong Wang ${ }^{1 *}$
\section{ABSTRACT}

This paper aims to clarify the relationship between extraversion and employees' innovative and disclose the moderating effect of organizational innovative climate on that relationship. To this end, 300 employees were selected from various enterprises in three Chinese cities, and subjected to a questionnaire survey based on the five factor model (FFM) and 5-point Likert scale. Through statistical regressions, the author explored the effects of extraversion and organizational innovative climate have on employees' innovative behavior. Then, the organizational innovative climate was divided into five dimensions, and the feature activation theory was implemented to reveal the moderating effect of each dimension on relationship between extraversion and employees' innovation. Through the above analysis, it is concluded that extraversion has a positive effect on employees' innovative behavior; the five dimensions of organizational innovative climate all exert a positive effect on employees' innovative behavior; the resource support in organizational innovative climate has a moderating effect on the relationship between extraversion and employees' innovation. The research findings shed new light on the improvement of organizational innovative and the construction of an innovative country.
\end{abstract}

Key Words: Extraversion, Employees' Innovative Behavior, Organizational Innovative Climate, Moderating Effect DOI Number: 10.14704/nq.2018.16.6.1604 NeuroQuantology 2018; 16(6):186-194

\section{Introduction}

Recent years has seen innovation being highlighted as a national strategy of China to gain sustainable competitive advantages. One of the essential parts of this strategy lies in enterprise innovation, the synthesis of the innovative behavior of employees. Against this backdrop, both enterprises and the academia are looking for better ways to encourage the innovation among employees, thus promoting organizational innovation (Xu, 2017; Shalley et al., 2004).

The innovative behavior of an employee depend heavily on his/her personality traits. The personality traits mirror the stable intrinsic psychological features of individuals, and bear on their thinking patterns, feelings and time-invariant behaviors. There are many methods to describe personality traits, such as the Sixteen Personality Factor Questionnaire (16PF) (Bahner, 2018), the Three Dimensional Personality (Li et al., 2014) and the five factor model (FFM) (Canale et al., 2017). Among them, the FFM, a.k.a. the Big Five personality traits, marks a major breakthrough in the research on personality traits (Jin and Wang, 2017). The FFM suggests five broad dimensions commonly used to describe the human personality: openness to experience, conscientiousness, extraversion, agreeableness and neuroticism (Zhang et al., 2017). Specifically, extraversion means high confidence and energy, and the preference towards social behaviors, that 
is, an extravert person tends to be positive, sociable and enthusiastic (Liu, 2010).

Over the years, much research has been done to disclose the direct effects of the five dimensions on the innovative behavior of employees. The existing studies mainly centre on two concepts: organizational innovative climate and employees' innovative behavior. The former refers to the employee's awareness of the innovation environment in an organization, including but not limited to the organizational policies, management behaviors and organizational flows (Amiable et al., 1996; Isaksen, et al., 1999). The latter refers to the employees' creation, introduction and implementation of ideas to the benefits of the organization and themselves, such as the development of new techniques and the streamlining of management routine (Janssen, 2000; Vuong et al., 2014; Su and Lin, 2018). In general, many scholars agree that extraversion has a positive effect on employees' innovative behavior. However, there is limited research on the effect of extraversion on a group of employees, not to mention a clear understanding of the influence mechanism (Mccrae and Costa, 1997).

To disclose the influence mechanism, this paper adopts the FFM to explore the effects of extraversion and organizational innovative climate on employees' innovative behavior, and the moderating effect of organizational innovative climate on the relationship between extraversion and employees' innovative behavior. The subjects are employees selected from various enterprises in three Chinese cities.

\section{Hypotheses}

\section{Extraversion and employees' innovative behavior}

As mentioned before, the FFM consists of five personality traits: openness to experience, conscientiousness, extraversion, agreeableness and neuroticism. Among them, extraversion is featured by energy, positive emotions, assertiveness, sociability and the tendency to seek stimulation in the company of others, and talkativeness. Extroverted people tend to be more dominant in social settings, opposed to introverted people who may act more shy and reserved in this setting.

In terms of employees' innovative behavior, extraversion has prominent positive effects on job satisfaction, job performance, organizational commitment, etc (Liang et al.,
2017). Extravert employees are more likely to pursue higher status and power. They are willing to take more risks at work, and create and implement new ideas. Through the above analysis, a hypothesis was put forward below.

H1: Extraversion is positively correlated with employees' innovative behavior.

\section{Organizational innovative climate and employees' innovative behavior}

Organizational innovative climate refers to employees' cognition of organizational policies, organizational flows, management behaviors and other factors that directly or indirectly support the innovation of an organization (Sun, 2014). This concept reveals the employees' judgement of whether the objective situation encourages their innovative behavior. Organizational innovative climate can be divided into five aspects: team support, leadership support, organizational philosophy, resource support and job flexibility. According to the feature activation theory, the effects of individual features on their behaviors are regulated by their cognition of the situation (Eckes et al., 2018). Ajzen and Fishbein pointed out the behavioral intention of individuals hinge on the organizational climate (Ajzen and Fishbein, 1980).

Once an employee perceives a positive organizational innovative climate, he/she tends to engage in innovation actively rather than passively. Organizational innovative climate inspires employees to care about organizational welfare and work to achieve organizational goals. The previous studies have revealed the positive impact of organizational innovative climate on employees' innovative behavior (Wang and Chang, 2017; Yan and Zhang, 2017). Through the above analysis, several hypotheses were put forward below.

H2: Team support is positively correlated with employees' innovative behavior.

H3: Leadership support is positively correlated with employees' innovative behavior.

H4: Organizational philosophy is positively correlated with employees' innovative behavior.

H5: Resource support is positively correlated with employees' innovative behavior.

H6: Job flexibility is positively correlated with employees' innovative behavior.

Moderating effect of organizational innovative climate on relationship between extraversion and employees' innovative behavior 
Organizational innovative climate has a certain impact on the motives, values, attitudes and behaviors of employees' innovation. If an employee is extravert, he/she is more likely to pursue innovation under incentives. One of the incentives is organizational innovative climate, which stimulates employees' innovative behavior and supports their innovation motives and attitudes (Zhu et al., 2017).

In many studies, organizational innovative climate is regarded as a major situational and dependent variable of innovative behavior. As stated by Schulte, organizational innovative climate, in the form of individual awareness, explains the varied degrees of satisfaction about the working environment among employees, in that employees tend to perceive the innovative actions taken by others. Under this climate, even those not that extrovert may positively interact with others and renovate their working methods. This is the only way for them to win the recognition of fellow workers. Thus, organizational innovative climate plays a role in the relationship between extraversion and employees' innovative behavior (Schulte et al., 2006). Through the above analysis, several hypotheses were put forward below.

H7: Team support moderates the effects of extraversion on employees' innovative behavior.

H8: Leadership support moderates the effects of extraversion on employees' innovative behavior.

H9: Organizational philosophy moderates the effects of extraversion on employees' innovative behavior.

H10: Resource support moderates the effects of extraversion on employees' innovative behavior.

H11: Job flexibility moderates the effects of extraversion on employees' innovative behavior.

\section{Methodology \\ Sampling}

The research objects are employees selected from steel, medicine, biology and education enterprises in Chengdu, Shanghai and Wuhan, three major cities in China. A total of 300 paper and online questionnaires were issued to these employees, who answered the questions in a voluntary yet anonymous manner. A questionnaire is deemed as invalid if more than 5 questions or 5 consecutive questions are not unanswered.
Finally, 278 (93\%) of valid questionnaires were recovered successfully. Among the respondents, $50.1 \%$ are males and $49.9 \%$ are females; the dominant age groups are 25 35 (46.9\%) and 35 45 (37.0\%); the leading education levels are undergraduate degree $(57.8 \%)$ and master degree $(31.5 \%)$; the primary work domains include technology research and development (56.4\%), quality and testing $(17.3 \%)$, production $(12 \%)$, sales $(6.7 \%)$ and administrative affairs (7.6\%); those who have worked for less than 1 year or over 5 years are distributed evenly across these domains; general staff and administrative staff take up about 58.2\% and $36.8 \%$, respectively. In general, the respondents can represent the general demographics of the working population in the three cities.

\section{Questionnaire design}

Each questionnaire consists of four parts, namely, basic information, extraversion, organizational innovative climate and employees' innovative behavior. For the latter three parts, the respondent had to evaluate their situation against a 5-point Likert scale (strongly disagree, disagree, neither agree nor disagree, agree, and strongly agree). There are three items in the extraversion part: "I prefer to be a leader rather than be led", "I want to be a team leader" and "I always actively participate in teamwork" (Zhang, 2013).

The part of organizational innovative climate was further split into 5 dimensions. First, there are 4 items on team support: "My colleagues always support and coordinate with each other at work", "My colleague are willing to share tips and techniques at work", "My colleagues frequently engage in communication and discussion at work", and "My colleagues often give advices on my new ideas). Second, there are 4 items on leadership support: "My superiors respect and tolerate the opinions and objections from their subordinates", "My superiors encourage their subordinates to ideas on improving production or service", "My superiors support and coordinate the creative work of their subordinates", and "My superiors set good examples of innovation. Third, there are 3 items on organizational philosophy: "My organization encourages employees to make new attempts and draw lessons from mistakes", "My organization appreciates innovative and enterprising employees", and "My organization rewards employees for their innovative ideas. Fourth, there are 4 items on resource support: "I 
have spare time to forge creative ideas or search for new methods", "I have access to facilities and devices to prove my new ideas", "I have access to adequate information and resource for creative work", and "I have plenty of time to realize my new ideas". Fifth, there are 4 items on job flexibility: "I can complete my tasks in my favourite way at work", "My job is very challenging", "I have the greatest say on my work", and "My creativity is fully displayed through the job arrangement" (Liu, 2011). The part of employees' innovative behavior contains 6 items: "I often have some creative ideas at work", "I am willing to share my new ideas with colleagues or superiors to solicit support and approval", "I will actively look for the resources to realize my creative ideas", "I will formulate proper plans to implement my innovative ideas", "I often give advice to my colleagues so that they can realize their innovative ideas", and "I am generally a creative person" (Liu and Shi, 2010).

\section{Statistic analysis method}

The data collected from the questionnaire survey were processed in SPSS 17.0 and SPSS AMOS 21.0. Specifically, confirmatory factor analysis was performed on SPSS AMOS 21.0 to examine the construct and discriminative validity of the scale, while reliability and validity test, improved exploratory factor analysis, descriptive statistical analysis and correlation analysis were conducted on SPSS 17.0 to identify data features and quality. Then, the effects of extraversion and organizational innovative climate on employees' innovative behavior were verified by hierarchical regression analysis, together with the moderating effect of various dimensions of organizational innovative climate on the relationship between extraversion and employees' innovative behavior.

\section{Empirical Analysis}

\section{Reliability and validity test}

This section discusses the data reliability and validity of the questionnaire survey. Validity stands for the correctness of the measuring model or the ability of the scale to measure the potential attributes of the objects. In theory, the average variance extracted (AVE) should exceed 0.5. The reliability, a.k.a. dependability, refers to the consistency of the results obtained by the same method or repeated measurements of the same object. According to the rest results in Table 1, the Cronbach's alpha, the indicator of reliability, was always above 0.70 , and the combination reliability
(CR) above the standard value of 0.6. This means the results obtained by the scale have good reliability. The AVE of the three variables was greater than 0.5 , revealing a good overall validity.

Table 1. Results of Reliability and Validity Test

\begin{tabular}{l|c|c|c}
\hline \multicolumn{1}{c|}{ Measurement index } & Cronbach's $\alpha$ & $C R$ & $A V E$ \\
\hline Extraversion & 0.716 & 5.641 & 0.700 \\
\hline Team support & 0.897 & 7.163 & 0.865 \\
\hline Leadership support & 0.915 & 8.982 & 0.807 \\
\hline Organizational philosophy & 0.905 & 7.917 & 0.835 \\
\hline Resource support & 0.828 & 5.274 & 0.813 \\
\hline Job flexibility & 0.772 & 4.860 & 0.791 \\
\hline Innovative behavior & 0.885 & 6.058 & 0.835 \\
\hline
\end{tabular}

\section{Improved exploratory factor analysis}

Since all measuring indices belong to the same questionnaire, the analysis results may be influenced by deviations of the common factor model. The traditional way to identify the problems induced by deviations is to test the nonrotating factors through an exploratory factor analysis on all variables. However, the traditional method can only determine a severe deviation when only one factor is being discussed or the explanatory power of a certain factor is particularly large. To solve the problem, the index of extraversion was combined with 1 dimension and 3 items, that of organizational innovative climate with 5 dimensions and 20 items and that of employees' innovative behavior with 1 dimension and 6 items. In this way, the traditional exploratory factor analysis was improved for analyzing non-rotating factors. The results were divided into 6 factors, explaining the total variance of $69.37 \%$. The largest factor variance explanation rate was $38.76 \%$, and the smallest was $3.82 \%$, which indicates that the influence of deviations is not serious.

\section{Confirmatory factor analysis}

The scale of the questionnaire survey was fitted by the structural equation model. As shown in Table 2 to Table 6, the three factor model outperformed the single factor model or two factor model in the fitting results of the sample data. Three factor model shows that the absolute compatibility indices of the scale reached the optimal goodness of fit $\left(\lambda^{2} / \mathrm{df}<3, \mathrm{GFI}>0.90\right.$ and RMESEA $<0.08$ ), and the value-added fitness index also met the optimal standard (GFI, TLI and CFI values all exceeded 0.09). Thus, the scale is wellstructured and compatible with our hypotheses. 
Table 2. Confirmatory Factor Analysis Model for Team Support

\begin{tabular}{l|c|c|c|c|c|c|c|c}
\hline \multicolumn{1}{c|}{ Model } & $\lambda^{2}$ & $d f$ & $\lambda^{2} / d f$ & RMSEA & CFI & TLI & RMR & GFI \\
\hline Three-factor model & 152.972 & 62 & 2.467 & 0.073 & 0.953 & 0.941 & 0.038 & 0.924 \\
\hline Two-factor model a & 404.514 & 64 & 6.321 & 0.139 & 0.823 & 0.785 & 0.077 & 0.825 \\
\hline Two-factor model b & 605.705 & 64 & 9.464 & 0.175 & 0.719 & 0.657 & 0.076 & 0.690 \\
\hline Two-factor model c & 352.311 & 64 & 5.505 & 0.128 & 0.850 & 0.818 & 0.057 & 0.850 \\
\hline Single-factor model & 804.668 & 65 & 12.380 & 0.203 & 0.616 & 0.539 & 0.088 & 0.650 \\
\hline
\end{tabular}

Note: Three-factor model: Extraversion; Team support; Employees' innovative behavior, Two-factor model a: Extraversion + Team support; Employees' innovative behavior, Two-factor model b: Team support + Employees' innovative behavior; Extraversion, Two-factor model c: Extraversion + Employees' innovative behavior; Team support, Single-factor model: Extraversion + Team support + Employees' innovative behavior

Table 3. Confirmatory Factor Analysis Model for Leadership Support

\begin{tabular}{l|c|c|c|c|c|c|c|c}
\hline \multicolumn{1}{c|}{ Model } & $\chi^{2}$ & $d f$ & $\chi^{2} / d f$ & RMSEA & CFI & TLI & RMR & GFI \\
\hline Three-factor model & 128.487 & 62 & 2.072 & 0.062 & 0.967 & 0.959 & 0.039 & 0.933 \\
\hline Two-factor model a & 399.163 & 64 & 6.237 & 0.137 & 0.834 & 0.789 & 0.087 & 0.824 \\
\hline Two-factor model b & 755.753 & 64 & 11.809 & 0.198 & 0.658 & 0.583 & 0.105 & 0.577 \\
\hline Two-factor model c & 328.443 & 64 & 5.132 & 0.122 & 0.869 & 0.840 & 0.058 & 0.858 \\
\hline Single-factor model & 943.701 & 65 & 14.518 & 0.221 & 0.565 & 0.478 & 0.112 & 0.608 \\
\hline
\end{tabular}

Note: Three-factor model: Extraversion; Leadership support; Employees' innovative behavior, Two-factor model a: Extraversion + Leadership support; Employees' innovative behavior, Two-factor model b: Leadership support + Employees' innovative behavior; Extraversion, Two-factor model c: Extraversion + Employees' innovative behavior; Leadership support, Single-factor model: Extraversion + Leadership support + Employees' innovative behavior

Table 4. Confirmatory Factor Analysis Model for Organizational Philosophy

\begin{tabular}{l|c|c|c|c|c|c|c|c}
\hline \multicolumn{1}{c}{ Model } & $\chi^{2}$ & $d f$ & $\chi^{2} / d f$ & RMSEA & CFI & TLI & RMR & GFI \\
\hline Three-factor model & 127.344 & 62 & 2.054 & 0.062 & 0.966 & 0.957 & 0.039 & 0.935 \\
\hline Two-factor model a & 395.905 & 64 & 6.186 & 0.137 & 0.827 & 0.789 & 0.085 & 0.825 \\
\hline Two-factor model b & 658.117 & 64 & 10.283 & 0.183 & 0.690 & 0.623 & 0.102 & 0.672 \\
\hline Two-factor model c & 327.270 & 64 & 5.114 & 0.122 & 0.863 & 0.833 & 0.057 & 0.860 \\
\hline Single-factor model & 858.329 & 65 & 13.205 & 0.210 & 0.587 & 0.504 & 0.111 & 0.634 \\
\hline
\end{tabular}

Note: Three-factor model: Extraversion; Organizational philosophy; Employees' innovative behavior, Two-factor model a: Extraversion + Organizational philosophy; Employees' innovative behavior, Two-factor model b: Organizational philosophy + Employees' innovative behavior; Extraversion, Two-factor model c: Extraversion + Employees' innovative behavior; Organizational philosophy, Single-factor model: Extraversion + Organizational philosophy + Employees' innovative behavior

Table 5. Confirmatory Factor Analysis Model for Resource Support

\begin{tabular}{l|c|c|c|c|c|c|c|c}
\hline \multicolumn{1}{c|}{ Model } & $\chi^{2}$ & $d f$ & $\chi^{2} / d f$ & RMSEA & CFI & TLI & RMR & GFI \\
\hline Three-factor model & 137.161 & 62 & 2.212 & 0.066 & 0.955 & 0.943 & 0.036 & 0.933 \\
\hline Two-factor model a & 363.132 & 64 & 5.674 & 0.130 & 0.820 & 0.780 & 0.065 & 0.844 \\
\hline Two-factor model b & 396.540 & 64 & 6.196 & 0.137 & 0.800 & 0.756 & 0.077 & 0.795 \\
\hline Two-factor model c & 338.083 & 64 & 5.283 & 0.124 & 0.835 & 0.799 & 0.058 & 0.858 \\
\hline Single-factor model & 590.674 & 65 & 9.087 & 0.171 & 0.683 & 0.620 & 0.086 & 0.742 \\
\hline
\end{tabular}

Note: Three-factor model: Extraversion; Resource support; Employees' innovative behavior, Two-factor model a: Extraversion + Resource support; Employees' innovative behavior, Two-factor model b: Resource support + Employees' innovative behavior; Extraversion, Two-factor model c: Extraversion + Employees' innovative behavior; Resource support, Single-factor model: Extraversion + Resource support + Employees' innovative behavior

Table 6. Confirmatory Factor Analysis Model for Job Flexibility

\begin{tabular}{l|c|c|c|c|c|c|c|c}
\hline \multicolumn{1}{c}{ Model } & $\chi^{2}$ & $d f$ & $\chi^{2} / d f$ & RMSEA & CFI & TLI & RMR & GFI \\
\hline Three-factor model & 129.468 & 62 & 2.088 & 0.063 & 0.956 & 0.945 & 0.038 & 0.934 \\
\hline Two-factor model a & 361.261 & 64 & 5.645 & 0.129 & 0.807 & 0.765 & 0.064 & 0.836 \\
\hline Two-factor model b & 264.775 & 64 & 4.137 & 0.106 & 0.870 & 0.842 & 0.052 & 0.860 \\
\hline Two-factor model c & 329.279 & 64 & 5.145 & 0.122 & 0.828 & 0.791 & 0.058 & 0.859 \\
\hline Single-factor model & 464.734 & 65 & 7.150 & 0.149 & 0.741 & 0.689 & 0.068 & 0.797 \\
\hline
\end{tabular}

Note: Three-factor model: Extraversion; Job flexibility; Employees' innovative behavior, Two-factor model a: Extraversion + Job flexibility; Employees' innovative behavior, Two-factor model b: Job flexibility + Employees' innovative behavior; Extraversion, Two-factor model c: Extraversion + Employees' innovative behavior; Job flexibility, Single-factor model: Extraversion + Job flexibility + Employees' innovative behavior 
Table 7. Mean, Standard Deviation and Correlation Coefficient $(\mathrm{N}=278)$

\begin{tabular}{l|c|c|c|c|c|c|c|c|c}
\multicolumn{1}{c|}{ Variable } & Mean & $\begin{array}{c}\text { Standard } \\
\text { deviation }\end{array}$ & $\begin{array}{c}\text { Extrave- } \\
\text { rsion }\end{array}$ & $\begin{array}{c}\text { Team } \\
\text { support }\end{array}$ & $\begin{array}{c}\text { Leadership } \\
\text { support }\end{array}$ & $\begin{array}{c}\text { Organizational } \\
\text { philosophy }\end{array}$ & $\begin{array}{c}\text { Resource } \\
\text { support }\end{array}$ & $\begin{array}{c}\text { Job } \\
\text { flexibility }\end{array}$ & $\begin{array}{c}\text { Innovative } \\
\text { behavior }\end{array}$ \\
\hline Extraversion & 3.363 & 0.858 & 1 & & & & & & \\
\hline Team support & 3.605 & 0.811 & $0.253^{* *}$ & 1 & & & & & \\
\hline Leadership support & 3.481 & 0.897 & $0.192^{* *}$ & $0.627^{* *}$ & 1 & & & & \\
\hline $\begin{array}{l}\text { Organizational } \\
\text { philosophy }\end{array}$ & 3.389 & 0.902 & $0.208^{* *}$ & $0.506^{* *}$ & $0.770^{* *}$ & 1 & & & \\
\hline Resource support & 3.119 & 0.901 & $0.324^{* *}$ & $0.392^{* *}$ & $0.510^{* *}$ & $0.629^{* *}$ & 1 & & \\
\hline Job flexibility & 3.327 & 0.800 & $0.247^{* *}$ & $0.434^{* *}$ & $0.491^{* *}$ & $0.540^{* *}$ & $0.553^{* *}$ & 1 & \\
\hline Innovative behavior & 3.414 & 0.766 & $0.390^{* *}$ & $0.465^{* *}$ & $0.417^{* *}$ & $0.411^{* *}$ & $0.469^{* *}$ & $0.520^{* *}$ & 1 \\
\hline
\end{tabular}

Note: ${ }^{*}$ respectively represent $p<0.01$

Table 8. Regression Coefficients of Extraversion, Organizational Innovative Climate and Employees' Innovative Behaviour

\begin{tabular}{l|c|c|c|c|c|c}
\hline \multicolumn{1}{c|}{ Predictive variable } & $\mathrm{t}$ & $\beta$ & $\mathrm{R}^{2}$ & $\triangle \mathrm{R}^{2}$ & $\mathrm{~F}$ value & $p$ \\
\hline Extraversion & 7.032 & 0.390 & 0.152 & 0.149 & 49.435 & 0.000 \\
\hline Team support & 8.729 & 0.465 & 0.216 & 0.213 & 76.188 & 0.000 \\
\hline Leadership support & 7.630 & 0.417 & 0.174 & 0.171 & 58.210 & 0.000 \\
\hline Organizational philosophy & 7.484 & 0.411 & 0.169 & 0.166 & 56.014 & 0.000 \\
\hline Resource support & 8.827 & 0.469 & 0.220 & 0.217 & 77.922 & 0.000 \\
\hline Job flexibility & 10.108 & 0.520 & 0.270 & 0.268 & 102.171 & 0.000
\end{tabular}

\section{Descriptive statistical analysis and correlation analysis}

Descriptive statistical analysis was performed on the sample data. Table 7 lists the mean, standard deviation and correlation between extraversion, organizational innovative climate and employees' innovative behavior. The results of correlation analysis show that extraversion is positively correlated with organizational innovative climate and employees' innovative behavior. These results lay the basis of subsequent discussion.

\section{Regression Analysis}

(1) Effects of extraversion and organizational innovative climate on employees' innovative behavior

The relationships among extraversion, organizational innovative climate and employees' innovative behavior were explored by multiple regression method. During the regression, the innovative behavior of all employees in an organization were considered as a whole, and the mean value of all items in each dimension of organizational innovative climate was taken as the organizational innovative climate score. According to the results in Table 8, extraversion had a significant positive effect on employees' innovative behavior $(\beta=0.390, p<0.01)$. The team support, leadership support, organizational philosophy, resource support and job flexibility all exerted significant positive effects on employees' innovative behavior, as evidenced by the results $(\beta=0.464, p<0.01),(\beta=0.417, p<0.01),(\beta=0.411$, $\mathrm{p}<0.01),(\beta=0.469, \mathrm{p}<0.01)$ and $(\beta=0.520, \mathrm{p}<0.01)$. Thus, Hypotheses H1 6 were all proved valid.
(2) Moderating effect of organizational innovative climate

The interaction variables of extraversion and organizational innovative climate were added to the regression model, aiming to reveal the moderating effect of organizational innovative climate on the relationship between extraversion and employees' innovative behavior.

Before the analysis on moderating effect, the independent variables and moderating variables were synthetized. Then, a regression model with a product term was used for hierarchical regression analysis. The analysis was implemented in the following steps. First, regress dependent variables to independent and moderating variables to obtain the determination coefficient moderation $R_{1}^{2}$. Second, regress dependent variables to independent variable, moderating variable and interaction term to obtain the coefficient moderation $\mathrm{R}_{2}^{2}$. The moderating effect should be considered significant if $R_{2}^{2}$ is significantly higher than $R_{1}^{2}$, and $\mathrm{p}<0.05$.

Through the above steps, the moderating effects of team support, leadership support, organizational philosophy, resource support and job flexibility were analyzed with gender, age, education background, work domain and years of working as control variables. The analysis results are shown in Table 9. With team support as the moderating variable, the values of $R_{1}^{2}$ and $R_{2}^{2}$ were 0.290 and 0.295 , respectively. Thus, $\mathrm{R}_{2}^{2}$ was greater than $R_{1}^{2}$. However, the interaction between extraversion and team support 
Table 9 Moderating Effect of Organizational Innovative Climate

\begin{tabular}{|c|c|c|c|c|c|}
\hline Dependent variable & Steps & Variable & $\beta(\mathrm{t})$ & $\triangle \mathrm{R}^{2}$ & F value \\
\hline \multirow{15}{*}{ Innovative behavior } & 1 & Extraversion & 5.553 & 0.290 & 57.632 \\
\hline & \multirow{2}{*}{2} & Team support & 7.481 & & \\
\hline & & Extraversion $*$ Team support & -1.641 & 0.295 & 39.556 \\
\hline & 1 & Extraversion & 6.139 & 0.268 & 51.817 \\
\hline & \multirow{2}{*}{2} & Leadership support & 6.790 & & \\
\hline & & Extraversion * Leadership support & -1.106 & 0.269 & 34.981 \\
\hline & 1 & Extraversion & 6.018 & 0.260 & 49.686 \\
\hline & \multirow{2}{*}{2} & Organizational philosophy & 6.518 & & \\
\hline & & Extraversion * Organizational philosophy & -0.763 & 0.259 & 33.267 \\
\hline & 1 & Extraversion & 4.919 & 0.278 & 54.335 \\
\hline & \multirow{2}{*}{2} & Resource support & 7.097 & & \\
\hline & & Extraversion * Resource support & $-2.176^{* *}$ & $0.288^{* *}$ & $38.293^{* *}$ \\
\hline & 1 & Extraversion & 5.520 & 0.338 & 71.776 \\
\hline & \multirow{2}{*}{2} & Job flexibility & 8.941 & & \\
\hline & & Extraversion *Job flexibility & -0.775 & 0.337 & 47.981 \\
\hline
\end{tabular}

$(\beta=-1.641, p>0.05)$ had no significant effect on employees' innovative behavior, indicating that the moderating effect of team support was not significant. The other dimensions of organizational innovative climate were analyzed in a similar manner. Through the analysis, it is learned that resource support is the only dimension of organizational innovative climate that has a certain moderating effect on the relationship between extraversion and employees' innovative behavior.

There was a significant interaction between extraversion and resource support. The regression coefficient of the interaction term between extraversion and resource support was negative, as shown in Figure 1. This means high extraversion actually weakened the positive effect of resource support on employees' innovative behavior, that is, the effect of resource support on employees' innovative behavior is low under a high level of extraversion. The inverse is also true. Thus, resource support does have a moderating effect and is a purely moderating variable. Consequently, hypothesis $\mathrm{H} 10$ was proved as valid.

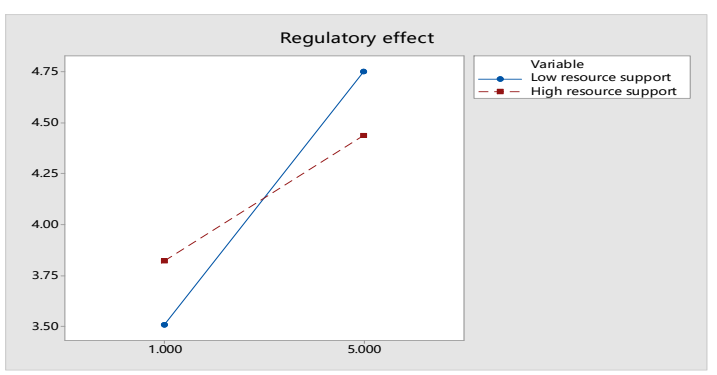

Figure 1. Interaction between Extraversion and Resource Support

\section{Conclusions}

This paper recovers the significant impact of extraversion on employees' innovative behavior. The employees' innovative behavior is adopted as the output variable, rather than routinely select extraversion as the antecedent variable. Meanwhile, the author investigated how the relationship between extraversion and employees' innovative behavior is moderated by five dimensions of organizational innovative climate. In this way, it is learned that resource support has a moderating effect on the relationship between extraversion and employees' innovative behavior: the higher the resource support, the greater the effects of extraversion on employees' innovative behavior. Thus, resource support enjoys a positive effect on organizational innovative climate. By contrast, the other dimensions of organizational innovative climate exert no moderating effect on the relationship between extraversion and employees' innovative behavior. Suffice it to say that this research pioneers the multi-dimensional and multi-sample research on the effects and influence mechanism of extraversion on a group of employees.

In light of the research findings, several suggestions were put forward for the human resources (HR) department in organizations. First, the HR managers should give more opportunities to employees with high level of extroversion, because extraversion has a positive effect on employees' innovative behavior. Second, organizations must provide employees with sufficient resources (e.g. funds, manpower, information and devices) for innovation, considering the moderating effect of resource 
support. Other measures include introducing well-established HR management system, setting up fair and just rules on remuneration and promotion, monitoring the self-innovative behavior of employees, providing smooth channels for internal communication, etc. Of course, this research also has its limitations, such as the overemphasis on individual-level variables and static effects. Therefore, the future research will fully demonstrate the effects of extraversion on employees' innovative behavior with a sample sufficiently large in size and diverse in sectors, and investigate if there are mediation factors (e.g. Chinese culture and self-efficacy) for the relationship between extraversion and employees' innovative behavior other than organizational innovative climate.

\section{Acknowledgements}

The whole research process is funded by National Natural Science Foundation of China (Grant nos. 71501019, 71501138, 71601164 and 71502019), China's Post-doctoral Science Fund Project (Grant no. 2018M631069), Ministry of Education Humanities and Social Sciences Research Plan Fund Project (Grant no. 15YJA630098), General Program of Education Department in Sichuan Province (Grant nos. 16SB0071 and 16SB0049), Key Program of Resource-based City Development Research Center (Grant no. ZYZXZD-1701), Key Program of Sichuan County Economic Development Research Center (Grant no. xy2017017), Funding Program for Middleaged Core Teachers of Chengdu University of Technology (Grant no. KYGG201519).

\section{References}

Ajzen I, Fishbein M. Understanding attitudes and predicting social behavior. Englewood Cliffs, NJ: Prentice-Hall 1980.

Amabile TM, Conti R, Coon H, Lazeby J, Herrom M. Assessing the work environment for creativity. Academy of Management Journal 1996; 39(5): 1154-84.

Bahner CA, Clark CB. Sixteen Personality Factor Questionnaire (16PF). Springer International Publishing, 2018.

Canale N, Vieno A, Bowden-Jones H, Billieux J. The benefits of using the UPPS model of impulsivity rather than the Big Five when assessing the relationship between personality and problem gambling. Addiction 2017; 112(2): 372-73.

Eckes A, Großmann N, Wilde M. Studies on the effects of structure in the context of autonomy-supportive or controlling teacher behavior on students' intrinsic motivation. Learning \& Individual Differences 2018; 62: 69-78.

Isaksen SG, Lauer KJ, Ekvall G. Situational Outlook questionnaire: A measure of the climate for creativity and change. Psychological Reports1999; 85(2): 665-74.
Janssen 0 . Job demands, perceptions of effort-reward fairness and innovative work behaviour. Journal of Occupational \& Organizational Psychology 2000; 73(3): 287-302.

Jin $\mathrm{H}$, Wang B, Management SO, University J. An empirical research on relationships among big five personality, employee guanxi and knowledge sharing behavior. Science \& Technology Management Research 2017; 21: 146-53.

Li N, Xu H, Xie F. Comparison of three-dimensional personality between smoking and non-smoking high school students. China Journal of Health Psychology 2014; 22(1): 84-86.

Liang F, Li SW, Sun R. the influence of organizational learning on organizational innovative performance from the perspective of SOR. Journal of Management Science 2017; 30(3): 63-74.

Liu Y, Shi JT. Does psychological empowerment mediate the relationship between organizational innovative climate and employee innovative behavior. China Soft Science, 2010(3): 133-44.

liu Y. an empirical research on the relationship between organizational innovative climate and employee innovative behavior from the perspective of psychological empowerment and motivational preference. Shanghai University of Finance and Economics 2011.

Liu Y. Research on the influence process of organizational innovation climate on employees' innovative behavior. Shanghai Jiao Tong University 2010.

Mccrae RR, Costa PT. Personality trait structure as a human universal. American Psychologist 1997; 52(5): 509-16.

Schulte M, Ostroff C, Kinicki AJ. Organizational climate systems and psychological climate perceptions: A cross level study of climate-satisfaction relationships. Journal of Occupational \& Organizational Psychology 2006; 79(4): 645-71.

Shalley CE, Zhou J, Oldham GR. The effects of personal and contextual characteristics on creativity: Where should we go from here? Journal of Management 2004; 30(6): 93358.

$\mathrm{Su}$ WL, Lin XQ. The Influencing of supervisor developmental feedback on employee's innovative behavior-the effect of core self-evaluation and work engagement. Science and Technology Progress and Policy 2018; 4(35): 101-07.

Sun ZY. Institutional choice in dispute settlement mechanism of regional trade agreements: A model based on transaction costs analysis. Jinan Journal (Philosophy and Social Sciences) 2014; (5): 59-68.

Vuong QH, Napier NK, Vu HK, Nguyen MC, Tran TD. Measuring corporate innovation capacity: Experience and Implications from I2Metrix Implementation in Vietnam. Social Science Electronic Publishing 2014; 1(1): 1-17.

Wang $\mathrm{H}$, Chang Y. The influence of organizational creative climate and work motivation on employee's creative behavior. Journal of Management Science 2017; 30(3): 51-62.

Xu YL. Universities' role in the national innovation system: A comparative analysis on the role of China and Japan. Japan Studies 2017.

Yan L, Zhang ZH. A mixed mechanism model of organizational innovation climate influencing the employee innovative behavior. Science Research Management 2017; 38(9): 97 105.

Zhang L, Lian ZH, Nie T. How does social support lead to performance? The mediated moderating role by work 
NeuroQuantology | June 2018 | Volume 16 | Issue 6 | Page 186-194 | doi: 10.14704/nq.2018.16.6.1604

Wang Z., Relationship between Extraversion and Employees' Innovative Behavior and Moderating Effect of Organizational Innovative Climate

family facilitation perspective. Business Management Journal 2017; 39(6): 116-28.

Zhang T. The effect of big five personality of the commercial bank's employees on the staff burnout: Perceived social support as mediating variables. Southwestern University of Finance and Economics 2013.
Zhu J, Lin J, Wang X. How online community climate influences members' innovation: An exploration from self-determination theory. Science \& Technology Progress \& Policy 2017; 34(8): 29-36. 